\title{
Emergency Medical Response in Mass Casualty Tunnel Incidents-with Emphasis on Prehospital Care
}

\author{
Annelie Holgersson ${ }^{1}$, Annika Eklund ${ }^{1,2}$, Lina Gyllencreutz ${ }^{1, *}$ and Britt-Inger Saveman ${ }^{1}$ \\ ${ }^{1}$ Department of Nursing, Umeå University, Umeå, Sweden \\ ${ }^{2}$ Division of Psychology, Pedagogy and Sociology, Section for nursing, University West, Trollhatten, Sweden \\ ${ }^{*}$ Corresponding author: lina.gyllencreutz@umu.se
}

Submitted: 8 August 2019 | In revised form: 26 November 2019 | Accepted: 14 December 2019 |

Published: 14 April 2020

\begin{abstract}
Responding to mass casualty incidents in a tunnel environment is problematic not least from a prehospital emergency medical services (EMS) perspective. The aim of this review was to 1) categorize preconditions for emergency response in tunnel environments based on Haddon's matrix and 2) identify specific EMS knowledge of providing prehospital care. Twenty eight articles, reports and book chapters were selected for further analysis. Firstly, sorting the data from each included article was done according to Haddon's matrix. The result covers human factors, technical factors, physical environmental factors and socioeconomic environmental factors all related to preconditions for emergency response. To describe the EMS's knowledge the data was also sorted according to command and safety, communication, assessment, and triage treatment and transport, also known as CSCATT. Few studies, especially of high quality, actually provide detailed information regarding emergency response to tunnel incidents and those that do, often have a main focus on management by the rescue service. While many incidents studied were caused by fires in tunnels, thus requiring rescue service in action, the subsequent EMS response issues that have taken place appear to have been given limited attention. To optimize the survival rates and health of the injured, as well as to provide a safe and effective work environment for the emergency services, there is a need to explore the event phase.
\end{abstract}

Keywords: emergency medical care; emergency response; major incidents; mass casualty incident; tunnels; prehospital care

\section{Introduction}

Mass casualty incidents (MCls) remain an extraordinary challenge for prehospital response. A number of studies of $\mathrm{MCls}$ have highlighted the need for further general knowledge in the areas of initial treatment and transport of patients [1], communication [2,3], joint training of emergency services [4], and call for more systematic reporting and research on possible associations between actions and outcomes to improve the emergency response [5]. The ramifications of incidents in difficult and confined environments, such as tunnels or other underground sites adds further challenges for emergency response and the outcomes can be devastating, as seen in the Baku Metro fire (289 people killed) [6] and the Daegu underground railway station fire (198 people killed) [7]. Other types of incidents are tunnel collapses, e.g. at a nuclear test site in North Korea (about 200 people killed) [8], which in turn, led to concerns about radiation and safety for personnel as 
half of the deaths occurred during prehospital response.

Increasing traffic frequencies, driving speeds, number of hazardous goods transports, and higher loading capacities constitute some risk factors for increased numbers of tunnel incidents $[7,9]$. While the probability of an incident in a tunnel can be considered comparatively low to on open roads $[9,10]$, the consequences are more extensive, measured in percentage of injured and killed [10-12]. Should a fire ensue, self-rescue will most likely determine chances of survival, given the speed with which a fire develops. However, some of the tunnel users may require assisted evacuation by emergency services i.e. rescue services (RS) and emergency medical services (EMS) [10]. Meanwhile emergency response to tunnel incidents may be impaired, because of limited access routes and possible traffic jams [10-12] as well as conditions in the tunnel, for instance impaired vision and extreme heat exposure in the case of a fire [13].

With regard to tunnel fires, stakeholders often have an overly optimistic view of the risk of an incident and its severity, combined with unrealistic expectations of emergency response and underestimation of the potential for loss of life [14]. Most of the existing literature on how to reduce the consequences of an incident investigate aspects such as smoke, ventilation, fire dynamics, construction, and risk assessment [15]. In the rare cases where the rescuers' perspectives regarding tunnel incidents have been studied, they focus on the RS [14-16] not the EMS response. The practical problem is thus that the tunnel environment directly increases the injurious effects of incidents while the EMS possibilities to respond and save life are inhibited. The scientific problem is that research has focused on primary prevention of technical issues related to fire or other emergencies and aiding self-rescue, but studies on EMS response to tunnel incidents are scarce.

The aim of this review is to 1) categorize preconditions for emergency response in tunnel environments based on Haddon's matrix and 2) identify specific EMS knowledge of providing prehospital care.

\section{Methods and Materials}

An integrative literature review generate new knowledge by means of a synthesis of representative literature [17]. In order to limit the risk of systematic errors [18] searches were conducted in several databases (MEDLINE/PubMed and EBSCOhost/ Academic Search Elite) in April 2018 for articles published in English between 1980 and 2018. In PubMed MeSH-terms were used. Additional several test searches with different terms, free text words and filters were conducted in both databases. Terms and wordings of interest in the searches were chosen in correspondence with the eligibility aspects a) tunnels/confined spaces, b)mass-casualty incidents, and c) pre-hospital response (Table 1). Slightly different keywords and clusters were used in the databases, as $\mathrm{MeSH}$ terms could not be used in Academic Search Elite. Tested words/terms did not add any records or generated only irrelevant records (Table 2).
Table 1. Eligibility and inclusion and exclusion criteria.

\begin{tabular}{l}
\hline Inclusion criteria \\
\hline (1) tunnels or confined spaces; \\
- includes a tunnel under construction or used for transport or \\
similarly confined space \\
AND \\
(2a) mass casualty incident(s); \\
- specified incident or compounded analysis from several \\
intentional or unintentional incidents \\
OR \\
(2b) compounded lessons from smaller incidents \\
- injury panoramas seen in similar environments, with implications \\
for large scale events \\
AND \\
(3) pre-hospital response; \\
- included pre-conditions for and/or specifics regarding the \\
prehospital medical care on site \\
\hline Exclusion criteria \\
\hline - Risk assessments or risk perceptions \\
- Crash frequency and cause \\
- Fire spread / dynamics, smoke movement, ventilation, heat \\
transfer, or gas temperature \\
- Behavior/ reactions in tunnel incidents \\
- Psychological aid for victims or responders \\
- Management and identification of human remains \\
- Industrial safety \\
\hline
\end{tabular}

Table 2. Search strings.

\begin{tabular}{|c|c|}
\hline PubMed & $\begin{array}{l}\text { ((“Confined Spaces"[mesh] OR “Subway*”[All Fields] } \\
\text { OR "Tunnel"”[All Fields]) AND ("Disasters"[mesh] OR } \\
\text { "Fires"[mesh] OR “Terrorism"[mesh] OR } \\
\text { "Accidents"[mesh] OR "rescue"[All Fields] OR } \\
\text { "Emergency Responders"[mesh] OR "Emergency } \\
\text { Medical Services"[mesh] OR “Emergency } \\
\text { Treatment"[mesh] OR "Critical Care"[mesh])) AND } \\
\text { "English"[Filter] }\end{array}$ \\
\hline $\begin{array}{l}\text { Academic } \\
\text { Search } \\
\text { Elite }\end{array}$ & $\begin{array}{l}\text { (("confined space" OR subway OR tunnel) AND } \\
\text { (disaster OR fire OR accidents OR emergency OR } \\
\text { rescue OR ambulance OR "emergency response" OR } \\
\text { "emergency management" OR "emergency medical } \\
\text { services")) + Limiters: Scholarly journals, English } \\
\text { language }\end{array}$ \\
\hline
\end{tabular}

For each title selected, additional titles of interest were also found through the box "related citations in PubMed" and through searches of the reference lists of the selected abstracts. Since relatively few relevant studies were found, we conducted an extended manual search for reports from tunnel incidents in Sweden (Swedish Accident Investigation Board) and Norway (Accident Investigation Board Norway), and it was decided that relevant books found in reference lists would also be included. Articles of interest were reviewed in a staged manner: firstly, through readings of their titles; secondly, the chosen abstracts and then the full texts were examined to confirm that they did 
not meet the exclusion criteria. To determine inclusion or exclusion of articles, relevance to the aim was deemed to weigh more than strict scientific standards and methodology. Studies from both real-life events and exercises were included.

\subsection{Screening for Relevance and Quality}

The primary database searches yielded 2343 articles, out of which 2308 were included in the title and abstract screening and another 35 were included from manual and reference searches (Figure 1). Many studies were excluded as they focused on questions of engineering aspects of tunnel safety (e.g. crash-prediction models or equations on technical aspects of fire-spread), leaving 61 texts for full text screening. Further review found that 28 scientific articles, reports and book chapters were deemed relevant and of scientific quality to merit inclusion. According to the evidence hierarchy used in the study (c.f. [19]) none of the included literature were systematic reviews or cross-sectional studies, but there were three high-quality modelling studies. Thirteen of the reviewed articles were medium-quality studies; one comparative case study and 12 case studies. Two non-systematic reviews/guidelines, nine special reports and one perspective article were identified as low-quality studies.

\subsection{Structure of Results}

To respond to the first part (1) of the aim i.e. categorize preconditions for EMS response in tunnel environments, the matrix of Haddon Jr. regarding injury prevention [20] was used. The data was applied to the matrix as a method for providing structure and to understand the content of the included articles. In the Haddon matrix, injury mechanisms (harmful energy) and their injury vector (energy carrier) [21] are sequentially separated over time versus their contributing factors, i.e. human, technical, and environmental. Environmental aspects may be further separated into physical and socioeconomic factors. In this study, the Haddon matrix was used in an adapted fashion as it is typically applied to a specific incident, not to compile a summary of factors found in studies containing many types of incidents. Additionally, some incident types (e.g., fires) are quite difficult to summarize in such a matrix as the incident is dynamic; the duration of "the event" is longer. This complicates determination of what constitutes an event as opposed to a post-event factor. Lastly, the actions of different actors (e.g. tunnel users, rescue personnel) are included in the matrix to portray the dual-response perspective. This is presented in the first section of the results.

To respond to the second part (2) of the aim i.e. identify specific knowledge of providing initial care, the Major Incident Medical Management and Support (MIMMS) framework [22] was utilized as it is familiar to many working in the prehospital environment; delineating the focus areas of Command, Safety, Communication, Assessment, Triage, Treatment and Transportation (CSCATTT). This is presented in the second section of the results.

\section{Results}

\subsection{Haddon's Matrix}

The factors that influence the outcomes and consequences of various tunnel incidents are divided into phases and summarized in Table 3.

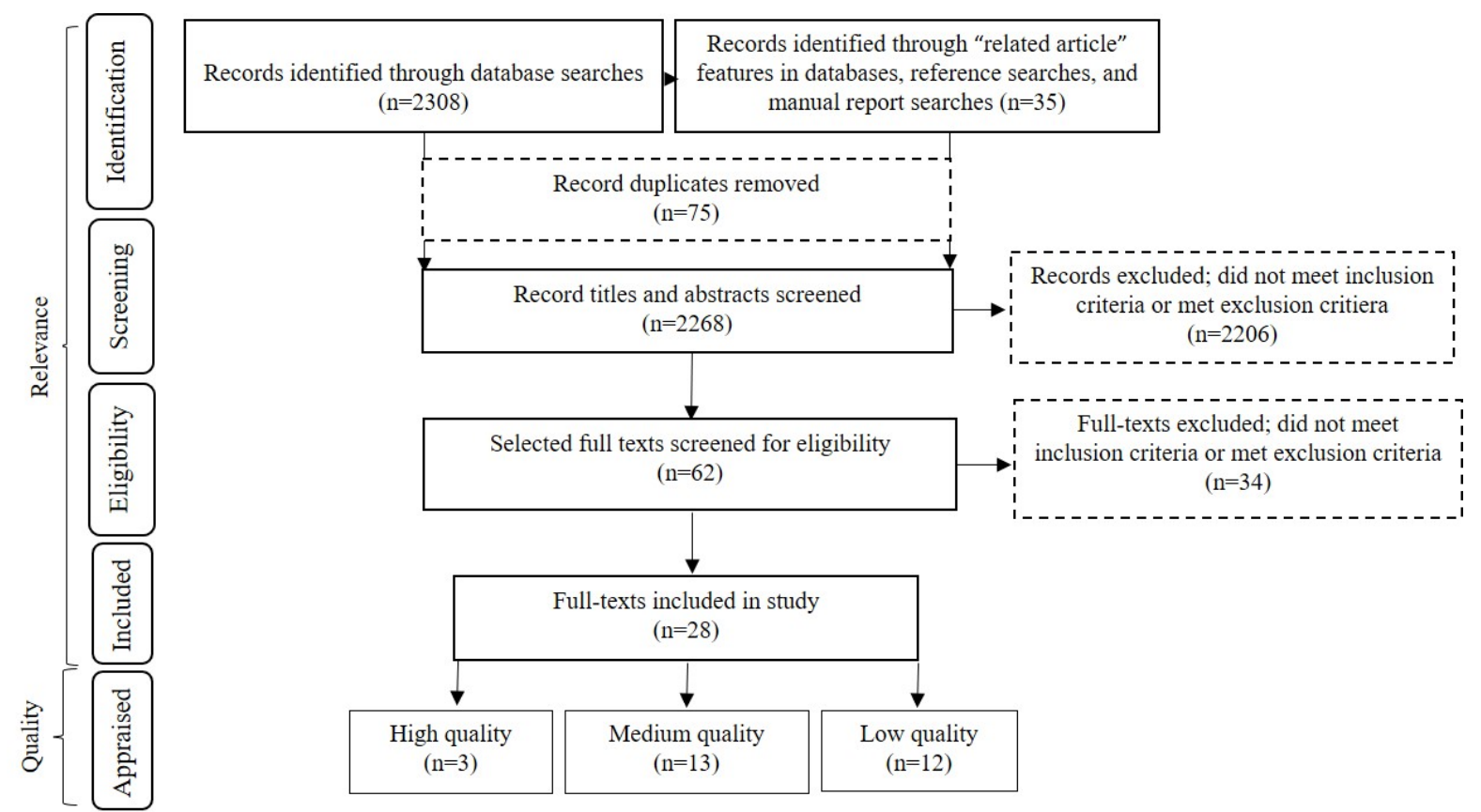

Figure 1. Study flow from identification through screening of relevance and quality. 


\subsubsection{Human factors}

In a tunnel fire the heat and smoke quickly create a fatal environment [23]. A tunnel fire test has shown that the level of smoke rises very rapidly and that an area can become completely engulfed in smoke in 5 minutes. Thus, it is crucial that the tunnel users swiftly evacuate and that emergency services reach the area quickly [24]. Meanwhile several studies have shown that people tend to stay in their vehicles [24-26] as they often do not recognize the seriousness of a fire and worry about their possessions [24]. This means that people are more willing to stay in the well-known and "safe" environment than to leave the car to evacuate [27]. Examples of this kind of delayed evacuation have been seen in several mass casualty tunnel fires, such as in the Mont Blanc tunnel [27]. Encouraging people to find and use emergency exits, if available, is reported as an issue as many instead evacuate towards the tunnel portals, as these are a familiar way out [27]. Through fire drills in tunnels or first-aider training the public can gain local knowledge and useful skills which makes them more inclined to find their way out of the tunnel and/or help others [28]. Knowledge of previous incidents can also be vital [29].

\subsubsection{Technical factors}

As many tunnel incidents have shown, actions taken in the pre-event phase are vital if the emergency response is to be achieved quickly [30]. This includes technical factors seen in installations in the tunnel and equipment for the public and the emergency services. To enable evacuation, emergency exits (less than $300 \mathrm{~m}$ apart), signage and auditory systems must be purposefully designed [24-26]. Additional aspects to enable emergency response include blast resistant lightings, high setting emergency lighting and signage visible through smoke $[24,26]$, as increased visibility eases rescue operations. Access to first aid equipment and portable fire extinguishers may also be helpful [30].

Communication issues during the response are wellknown and common in mass casualty incidents due to overload of mobile network, and presents an even greater challenge in the tunnel environment where mobiles and radios are often non-functional [28,30-36]. An installed radio communication system can facilitate communication between different services [23]. Personal mobiles and available mobile network infrastructure can allow data sharing and dissemination of information in and across organizations [37]. Another important issue for the EMS response is a functional fire detection system, heat sensors and monitoring and surveillance equipment $[23,26]$, to identify the precise location of the fire [29]. A fire detection system being out of service and lack of knowledge of fire location can delay emergency response [25,29]. While some tunnels have 24-hour monitoring system, fire-fighting facilities, fire trucks and dedicated response teams, others are dependent on aid by emergency services and supply emergency recesses [23,30]. Other specialized equipment for EMS responders who deal with tunnel incidents include extended duration breathing apparatus, personal protective equipment (PPE), head lamps and extra oxygen for casualties $[30,32,34,38]$.

In confined spaces such as subway architecture, fire gas might disperse less rapidly than it does in an open space [39]. Fire ventilation can enable responders to better fight the fire [23] and enable a quick emergency response. In a twin tube tunnel fire, the smoke will probably be vented and fire extinguishing can begin in a smoke-free environment. However, the same fire in a single-tube tunnel can cause major difficulties in terms of extinguishing the fire depending on whether the smoke can be vented. Without the possibility of fire ventilation, the fire may require an advanced smoke diving operation before the fire extinguishing can begin [27]. This, in turn, delays the response and worsens the situation leading to several deaths and injuries [26]. One conclusion, in terms of response to large tunnel fires, is that focus should be on providing ventilation. The duration of exposure to smoke is very important for the outcome [31]. Natural ventilation may also play a role as shown by an incident where four people who were exposed to smoke for one hour survived due to beneficial winds, which allowed for some breathable air $[26,40]$. The wind can also have detrimental effects [23].

\subsubsection{Physical environmental factors}

The pre-event phase, (i.e., planning of tunnel safety), calls for an integrated approach that takes the whole environment into account, including the users, vehicles, transported goods, infrastructure, and responders [41]. Tunnel design aspects, such as its length, number of tubes, bi or unidirectional traffic flow, provision of a service tunnel and fresh air ducts, have implications for emergency response [30]. Moreover, escape galleries or lighted air-locked corridors allow for users to evacuate the tunnel and may also provide storage for smaller evacuation vehicles. Train tunnels emergency stations may provide passengers the opportunity to access an evacuation tunnel or communication branches may allow passengers to evacuate through a train on the opposite side. Refuges, allocated evenly along the tunnel, are made to protect tunnel users from the direct atmosphere of the tunnel by ventilation through fresh air ducts and a light under-pressure which imposes an air flux [23]. It is vital that emergency call niches are not confused with escape galleries or refuges [29]. What might happen when risks are underestimated and emergencies not considered during construction, are e.g. that tunnels may not have emergency routes nor lighting, no means of communication or to open the doors for the passengers [33].

Also, the fact that many tunnels and subway environments are outdated, i.e., designed and built a long time ago, and for other types of vehicles and less traffic, impact the emergency response. For example, the deep tube lines in London are designed with only a $15 \mathrm{~cm}$ clearance around the carriages and the tunnel sides, which severely impacted access and evacuation in the London bombing 
[42]. Moreover, confined spaces such as subway trains, buses and tunnels exacerbate effects of bomb detonations since surface reflections amplify and prolong the blast wave. In turn, the blast wind is channeled, and heat and gases are contained $[35,42]$. Thus, the severity of injuries among survivors and mortality is greater in confined space bombings compared to explosions in open-air environments [32,43].

\subsubsection{Socioeconomic environmental factors}

Organizational aspects, such as tunnel operator and emergency responders, and contextual resources, like hospitals, helipads and water resources, are crucial for EMS response in tunnels [41]. All elements need to be considered together in a so-called safety chain related to pre-event, event and post-event phases; including actions to prevent hazards, reduce the probability and lessen consequences of incidents by increasing preparedness among emergency responders [25]. Contingency plans need to be jointly developed in order to secure a coherent and coordinated approach to information sharing and incident management, as well as opportunities for continued improvements [30,44].

The importance of responders that are specifically trained and experienced in challenging tunnels and subways environments, might require extrication skills $[32,38$, $41,44,45]$. As the responders from the police, EMS and $\mathrm{RS}$ are dependent on each other's actions during incident management, they also need to be co-trained [34]. The distribution of roles and responsibilities in relation to other tunnel staff should be clearly defined [41]. The training of train/subway staff to deal with emergency situations is also important, as these can play vital roles in reducing time for evacuation. The station staff at fire at King's Cross underground station lacked training in dealing with such an incident, which led to actions that actually contributed to the catastrophe [26]. Other incidents have shown that leaving responders to solve problems in tunnel incidents only by using tactics they are familiar with could be detrimental to the outcome [46]. Meanwhile the presence of experienced EMS responders on scene of incidents have allowed for life-saving and advanced interventions [42,45]. Being able to carry out such procedures is also dependent on actions in the pre-event phase, such as legislation e.g. when EMS responders' use of endotracheal tube or laryngeal mask to maintain airways was not allowed without permission [34]. The lack of legislation regarding tunnel safety has also meant little perceived need or motivation to make investments to aid emergency response [33].

\subsection{Specific EMS Issues to $\mathrm{MCl}$ in Tunnels}

The following sections presents an analysis of specific EMS knowledge structured by CSCATT in tunnel incidents.

\subsubsection{Command and Safety}

Scene safety is pointed out as a huge concern in tunnel incident scenarios $[25,32,42]$. Scene safety assessment includes different types of issues: 1) Environmental (e.g. confined space, heat, hazardous materials, collapse); 2) Biological (e.g. sharps and debris, positive infective risks); 3) Chemical (e.g. smoke, combustion products, particulate matter), and 4) Electrical (in the event of incident in train/subway tunnel). Furthermore, there may be intentional dangers, if the incident had an antagonistic cause $[25,26,32,42]$. In addition to these direct threats for EMS responders and victims there may be indirect threats in tunnel environments that result in danger depending on subsequent events [25]. Challenging working conditions described by the EMS include lighting problems, high temperatures, poor ventilation, obstructed access and contamination by smoke, debris and dust [25,32,35].

\subsubsection{Communication}

Challenges regarding communication are par for the course during incident response, and these issues are often augmented by an incident scene in a tunnel. There are several reasons for this. Firstly, technical difficulties commonly hamper communication in tunnel environments, which may isolate EMS responders from dispatch centers [32,38]. Secondly, two command posts and evacuation sites are often set up, since tunnel users escape in two directions, implying additional needs for coordination $[31,32,38]$. Thirdly, the two command posts may report to different dispatch centers if the involved organizations belong to different districts or even different countries [29,31,38]. Lastly, some tunnels have different operators responsible for different sections of the tunnel, who also need to be included in the response [30]. Meanwhile the ability to manage the incidents significantly decreases if communication infrastructure fails by hampering communications between EMS responders, dispatch centers and hospitals. This in turn affect patient distribution with the risk of overwhelming receiving hospitals $[34,35,39]$. Suggestions for overcoming communication difficulties on scene include using runners or cars $[28,31]$, reserving priority lines in the mobile phone network, and using loudspeakers and megaphones to inform crowds [46].

\subsubsection{Assessment}

In terms of assessment, the tunnel environment typically means difficulties for the EMS to get an overview of the scene, which is necessary to determine what is happening and suitable tactics. This hampers the gathering of information by the EMS and means important decisions on what actions to take in the initial stages of response must be made on available and limited information, which may delay response [26,27]. One method used to gain information for assessment is through monitoring equipment installed in the tunnel combined with predetermined, well-thought-out communication and user interface. One study conclude that reduced visibility is the first critical mechanism that limits EMS assessment possibilities. Heat is the second mechanism that impedes emergency response or fire-fighting possibilities. Carbon monoxide does not pose a real threat 
to EMS responders with breathing apparatus, whereas the effect of falling rubble is a psychological barrier [25].

Suitability of the chosen assessment tactic depends on the type of fire, surrounding premises and number of people involved, which makes information gathering for EMS assessment one of the most important sub-goals initially. Another vital focus of assessment may be on the prevention of uncontrolled escalation of an incident, especially in tunnels that are imbedded in soft soil or beneath water level as the consequences could be catastrophic if the integrity of such tunnels failed [25].

The need for EMS responders and their effectiveness in versus outside the tunnel environment has to be considered and evaluated in each case. In several cases RS have transferred casualties from the most hazardous area on-scene to a place where EMS responders have taken over [31,36]. If an approach of advanced care by the EMS in a safe environment is chosen, it will amount to a very resource intensive effort if the number of injured people is large [27]. Quickly moving the first found people is not always the most effective life-saving effort [27]. However, in the aftermath of an explosion rapid removal of seriously injured with minimal medical intervention may be an appropriate response [32]. In the response to the Gudvanga tunnel fire, EMS were released into the tunnel to pick up road users after the fire was determined to be under control, but the EMS responders turned around as they considered the area unsafe without protective equipment [31]. There have also been instances where medically trained personnel among the public and EMS responders have died while trying to help casualties [36].

\subsubsection{Triage, Treatment and Transport}

The last three elements during incident response are more focused on the casualties and concern Triage, Treatment and Transport. Rapid arrival to the scene may be especially problematic for tunnel incidents as the transportation infrastructure itself is affected, which often results in road congestion $[35,38]$. Depending on whether it is an urban or rural scene some access issues may be overcome through use of bicycles, helicopters and reversal of traffic direction on certain stretches of road $[35,38,45]$. Delayed dispatch, arrival or timing problems on scene have also resulted due to long distance to reach the injured, safety concerns, confusion regarding number of incidents or injured [32,38,47]. Delayed response in combination with an incident development that often is rapid, constitute some factors why response to tunnel incidents is normally thought of as a twophase process; an initial phase, which includes detection, alarm and self-rescue, followed by the emergency response intervention phase [44].

The most common types of tunnel incidents mentioned in the articles were fires, bombings, and tunnel collapses. Therefore, the treatment section focuses on inhalation injuries, blast injuries and crush injuries. In fire incidents, there have been instances were casualties have had burns on their skin even though their clothes have appeared unharmed. This was seen in the King's Cross fire where people needed to be hosed down prior to treatment, as their clothes were too hot to touch [36]. Considering smoke inhalation injury it is of utmost importance to realize that exposure to smoke in a tunnel will continue even though the fire is put out, dependent on natural wind and use of ventilation [31]. Tunnel fires often result in long-term smoke exposure and relatively high smoke intensity and might be associated with additional complications as they can easily induce systemic poisoning $[31,48]$. Some of the most common mechanisms are absorption of toxic gases in the blood, inhalation of soot particles, and inhalation of bronchopulmonary toxins/irritants [31]. The presence of soot and facial burns suggest a thermal lesion, which indicates direct cell injury and is associated with swelling and may complicate the first 24 hours of treatment. As stated, in confined spaces the reflection of blast waves from walls and other surfaces creates complex waves of longer duration, which allow greater transfer of energy to the body, thereby increasing the risk of primary blast injuries. Moreover, inhalation of carbon monoxide and cyanide may cause systemic poisoning; a frequent and lethal problem resulting from fires in confined spaces. The main treatment consists of administering complementary oxygen until the injured person becomes asymptomatic. Death caused by hydrogen cyanide is not uncommon in casualties due to the burning of plastics [36]. Supplemental oxygen (100\%) is recommended in mild cases while patients with severe symptoms may benefit from methylene blue or transfusion of red blood cells [48].

In case of collapse, some casualties become entombed which makes post-collapse rescue difficult, requiring sophisticated rescue resources and pose significant risk to the responders themselves [49]. Besides calling out, listening for knocks and shouts and asking others in the rubble if they see or hear anyone, IR-cameras can be used to scan the area for body heat emissions and some defibrillators also have the ability to check for the presence of $\mathrm{CO}_{2}$, which is a strong indication that someone is breathing in the confined space. EMS responders with advanced life support training often carry medications to pre-treat a crush injury casualty [50].

Common problems initially in terms of transport include limited availability of ambulances and possibly long transportation times, depending on scene location [38]. These challenges are mitigated during rush hour and night-time thanks to a higher likelihood of available helicopters for transportation and transfer of resources and personnel $[31,32,45]$. Other cars and buses have also been used to augment transportation capabilities $[31,38]$. While far from standard Danish RS, have special rescue vehicles which can drive on both road and rail and can thus perform rescue in both types of tunnels [44]. Descriptions of included references is shown is Table 4. 
Table 3. Factors influencing consequences of various tunnel incidents* compounded into Haddon matrix.

\begin{tabular}{|c|c|c|c|c|}
\hline \multirow{2}{*}{$\begin{array}{l}\text { Factor } \\
\text { Phase }\end{array}$} & \multirow{2}{*}{$\begin{array}{l}\text { Human factors }(\#)^{\star *} \\
\text { A }\end{array}$} & \multirow{2}{*}{$\begin{array}{l}\text { Technical factors }(\#)^{\star \star} \\
\text { B }\end{array}$} & \multicolumn{2}{|c|}{ Environmental factors $(\#)^{\star \star}$} \\
\hline & & & C Physical & D Socioeconomic \\
\hline \multirow[t]{4}{*}{1 Pre-event } & Alcohol/ substance use [40] & $\begin{array}{l}\text { Traffic speed, volume and other } \\
\text { traffic management aspects } \\
{[30,38,41]}\end{array}$ & $\begin{array}{l}\text { Tunnel design, construction } \\
\text { material \& maintenance } \\
{[30,40,41,46]}\end{array}$ & $\begin{array}{l}\text { Preparedness/disaster plans \& } \\
\text { testing }[24,30,39,46]\end{array}$ \\
\hline & Fatigue [30] & & Uni- or bidirectional traffic [30] & $\begin{array}{l}\text { Integrated tunnel safety approach } \\
\text { \& safety-chain }[25,27,41]\end{array}$ \\
\hline & Distraction [30] & & & $\begin{array}{l}\text { Provision of emergency } \\
\text { education \& training }[34,44]\end{array}$ \\
\hline & $\begin{array}{l}\text { Understanding of safety } \\
\text { advice/announcements [30] }\end{array}$ & & & $\begin{array}{l}\text { Policies \& legislations on tunnel } \\
\text { safety }[33,40]\end{array}$ \\
\hline \multirow[t]{4}{*}{2 Event } & Age-related health status $[31,33]$ & $\begin{array}{l}\text { Speed, size, \& load of vehicle } \\
{[33,40]}\end{array}$ & $\begin{array}{l}\text { Distance to emergency exits } \\
{[26,41,44,46]}\end{array}$ & $\begin{array}{l}\text { Training, co-training and } \\
\text { experience of emergency } \\
\text { responders } \\
{[23-26,30-32,34,41,44-46]}\end{array}$ \\
\hline & $\begin{array}{l}\text { Pre-existing conditions } \\
{[23-27,29,31,42,43]}\end{array}$ & Fire extinguishers $[28,29,38]$ & $\begin{array}{l}\text { Evacuation tunnels or branches } \\
\text { to evacuation trains }[29,30,33]\end{array}$ & \\
\hline & & $\begin{array}{l}\text { Use of ventilation \& jet fans } \\
{[23,26,31]}\end{array}$ & $\begin{array}{l}\text { Escape galleries or refuges } \\
{[23,25,30]}\end{array}$ & \\
\hline & & $\begin{array}{l}\text { Sprinkler, hydrant \& drainage } \\
\text { system }[24-27,40,44]\end{array}$ & $\begin{array}{l}\text { Containment of blast wave, heat, } \\
\text { gas \& smoke } \\
{[26,31,35,39,40,42,43]}\end{array}$ & \\
\hline \multirow[t]{6}{*}{3 Post-event } & $\begin{array}{l}\text { Ability, knowledge of \& } \\
\text { willingness to self-evacuate } \\
{[23,25-29,32,33,40]}\end{array}$ & $\begin{array}{l}\text { Water supply \& electrical power } \\
\text { function [38] }\end{array}$ & $\begin{array}{l}\text { Site access, lay-bys \& } \\
\text { turning-bays }[30-32,42]\end{array}$ & $\begin{array}{l}\text { Response by tunnel operator, } \\
\text { on-site rapid response team, \& } \\
\text { external rescue organizations } \\
{[25-27,29,30,33,36,39,41,42,44-} \\
46,48-50]\end{array}$ \\
\hline & $\begin{array}{l}\text { First-aid training and skills among } \\
\text { injured and bystanders }[28,49]\end{array}$ & $\begin{array}{l}\text { Emergency lighting, signage \& } \\
\text { auditory system [38] }\end{array}$ & & \\
\hline & & $\begin{array}{l}\text { Personal protective equipment \& } \\
\text { specialist equipment } \\
{[27,30,34,38,39,44]}\end{array}$ & $\begin{array}{l}\text { Fire-fighting facilities or } \\
\text { emergency recesses }[30,46]\end{array}$ & Legal restraints on EMS [34] \\
\hline & & $\begin{array}{l}\text { Fire detection system and } \\
\text { monitoring [30] }\end{array}$ & $\begin{array}{l}\text { Tunnel length and height } \\
{[25,30,44]}\end{array}$ & $\begin{array}{l}\text { Ambulance \& helicopter } \\
\text { availability }[23,32,35,38,45,47]\end{array}$ \\
\hline & & First aid equipment $[30,50]$ & $\begin{array}{l}\text { Single or double-tube tunnel } \\
{[27,30]}\end{array}$ & Alternative vehicles $[23,35,38]$ \\
\hline & & $\begin{array}{l}\text { Available \& functional internal } \\
\text { and external communication } \\
\text { networks }[23,28,30,32-37,46]\end{array}$ & Urban/rural location $[33,38]$ & $\begin{array}{l}\text { Contextual resources: hospitals, } \\
\text { helipads, water [41] }\end{array}$ \\
\hline
\end{tabular}

* The matrix is usually used to analyze a particular incident, but here data e.g. from tunnel fires, bombings and crashes have been compounded into the same table. ${ }^{\star *}$ Numbers (\#) refers to reference number (\#) in "Table 4. Description of included references".

Table 4. Description of included references.

\begin{tabular}{|c|c|c|c|}
\hline $\begin{array}{l}\text { Ref. } \\
\text { \# }\end{array}$ & Authors, year and title & $\begin{array}{l}\text { Study design, type } \\
\text { of tunnel (scor- } \\
\text { ing/quality) }\end{array}$ & Main findings/major factors according to Haddons matrix \\
\hline [23] & $\begin{array}{l}\text { Vuilleumier et al., } 2002 . \\
\text { Safety aspects of rail- } \\
\text { way and road tunnel: ex- } \\
\text { ample of the Lötschberg } \\
\text { railway tunnel and Mont- } \\
\text { Blanc road tunnel }\end{array}$ & $\begin{array}{l}\text { Special report, Road } \\
\text { and rail tunnels } \\
\text { (Low) }\end{array}$ & $\begin{array}{l}\text { A3 \& D3: Limited time for self-evacuation and EO response. A2-A3 \& D3: Scene approach or evacua- } \\
\text { tion should not take place. B2: Fire ventilation can enable self-rescue and rescue. Equipment and staff } \\
\text { in fire-fighting facilities important. Closed-circuit cameras and heat sensors to aid detection. B3: Radio } \\
\text { systems can facilitate communication. C2: Escape galleries may allow for self-rescue and smaller evacu- } \\
\text { ation vehicles to hel injured and disabled. Allocation and function of refuges, emergency and fire-fighting } \\
\text { recesses important. Lay-bys and turning bays may facilitate rescue. For train tunnels emergency stations } \\
\text { may provide passengers the opportunity to access an evacuation tunnel or communication branches may } \\
\text { allow passengers to evacuate through a train on the opposite side. }\end{array}$ \\
\hline
\end{tabular}


Table 4. Continued.

\begin{tabular}{|c|c|c|c|}
\hline $\begin{array}{l}\text { Ref. } \\
\#\end{array}$ & Authors, year and title & $\begin{array}{l}\text { Study design, type } \\
\text { of tunnel (scor- } \\
\text { ing/quality) }\end{array}$ & Main findings/major factors according to Haddons matrix \\
\hline [24] & $\begin{array}{l}\text { Ernst et al., } 2006 . \\
\text { Underground trans- } \\
\text { portation systems in } \\
\text { Europe: safety opera- } \\
\text { tions and emergency } \\
\text { response }\end{array}$ & $\begin{array}{l}\text { Non-systematic } \\
\text { review/ Guidelines, } \\
\text { Road and rail tun- } \\
\text { nels (Low) }\end{array}$ & $\begin{array}{l}\text { A2: Human behavior in tunnel fires. B2: Evacuation signage, evacuation system, alarm system, light- } \\
\text { ing options, communication system for selfrescue purposes. D1: Disaster plans. D2: Education and } \\
\text { exercises for emergency personnel. D3: Communication difficulties. }\end{array}$ \\
\hline [25] & $\begin{array}{l}\text { Rosmuller \& Van den } \\
\text { Brand, 2003. Emer- } \\
\text { gency response possi- } \\
\text { bilities at freight railway } \\
\text { tunnel accidents }\end{array}$ & $\begin{array}{l}\text { Special report, Road } \\
\text { \& Rail tunnels (Low) }\end{array}$ & $\begin{array}{l}\text { A2-A3: Self-rescue passivity. B2 \& C2: Inability to find escape doors. C1-C3 \& D1-D3: Rescue focus- } \\
\text { ing on preventing escalation vital in tunnels in soft soil or beneath water level due to catastrophic con- } \\
\text { sequences if tunnel fails. D1-D3: Robust tunnel safety relies on a safety chain considering pro-action, } \\
\text { self-rescue, preparation and repression. Response depend on the physical mechanisms and capacities } \\
\text { of emergency responders. Uncertain if emergency organizations will enter threatened tunnel. Response } \\
\text { in freight railway tunnels are extremely limited. Upon arrival the physical conditions have already dete- } \\
\text { riorated so much that hardly anything can be gained from intervention. Rescue service for offensive } \\
\text { emergency response tactics only for operations involving small fires or minor leaks of hazardous mate- } \\
\text { rials. The physical capacities are restricted by heat absorption and harsh working conditions. Reduced } \\
\text { visibility are the critical mechanism that limits response possibilities oxid heat. Carbon monoxide does } \\
\text { not pose a real threat to RS units, but falling rubble is a psychological barrier. }\end{array}$ \\
\hline
\end{tabular}

[26] Bergqvist et al., 2005. Fire and rescue operations in tunnel fires: a discussion of some prac-

Special report, Road \& Rail tunnels (Low)

A2-3 \& C2: Self-rescue reluctance. Self-evacuation highly dependent on distance to a safe environment B2: Tunnels should have a permanently installed hydrant system. Emergency exits and signage must be purposefully designed. Examples of positive and negative effect of natural ventilation. Dire consequences can amount from wrong decision regarding ventilation. Clean air needed to reduce the toxicity thus focus should be on providing ventilation to facilitate self-rescue. This requires a lot of information. Monitoring and surveillance equipment can provide needed information. C2: In a tunnel fire the gases will not dissipate in the same way as in a house fire. How far fire gases extend depend e.g. on the roof height of the tunnel. D2: Train crew need emergency training to reduce evacuation time or their actions might contribute to the catastrophe. Management by staff play an important role during emergencies. D3: Determination of incident cause and scene overview difficult which causes coordination problems. Ventilation may obscure origin of fire. Lack of information a problem for rescue. Decisions on actions to take based on available, limited information. Practical fire trials have shown risk of collapse of tunnels. Trains and electrical current pose hazards. Communication is vital for coordination and safety of personnel.

[27] Ingason et al., 2005. Modelling study, Rescue in road tunnels Road tunnel (High)

A2-A3: Delayed self-evacuation. B2: Need for clear signs to encourage self-evacuation. Drivers who see other people evacuate are more likely to also do so. Many evacuate towards the tunnel portals. B3: Monitoring equipment combined with a predetermined communication and user interface aids gathering of information. Reconnaissance by vehicle or on foot with IR-cameras and lighting cables may be helpful. C3-D3: Single-tube tunnel fire cause difficulties in fire extinguishing and rescue. D1: Those responsible for safety underestimate challenges. D3: Rescue service may not have appropriate work methods, materials or personnel. Different methods by the rescue services usually combined to form a viable rescue effort. Suitability of the chosen method depends on the type of fire, surrounding premises and number of people involved. Gathering information often hampered by an inability to over-view the scene.

[28] Bruyelle et al., 2014. Improving the resilience of metro vehicle and pas-

Case study, Subway (Medium)

A3: Important to view casualties as actors, capable of helping themselves and one another. Fire drills or first-aider training are vital since people with local knowledge and useful skills are more inclined to help others. B2-B3: Inability to open side doors in carriage hinders evacuation. Blast resistant emergency lighting and signage, visible through smoke may help improve evacuation. Blasts and underground location impacts communication equipment. Absence of first aid equipment impedes help from medically trained bystanders. emergency response to terrorist attacks

[29] Voeltzel \& Dix, 2004. A comparative analysis of the Mont Blanc, Tauern and Gotthard tunne fires

Comparative case study, Road tunnel (Medium)

A2: Self-rescue essential. A3: Awareness by users has impact on self-evacuation decision. B2: Fire detection system out of service. Detecting the precise location of the fire is imperative. Tunnel users could not extinguish fires with fire extinguishers provided. C2: Fatalities from heat in shelter. Vital that emergency call niches and are not confused with evacuation routes or pressurized shelters. D3: On-coordinated control centers at each end of tunnel.

[30] Burns, 2005. Emer- Special report, Road gency preparedness in road tunnels: current practice and future tunnel (Low)

A1: In tunnels on major international routes tunnel users may be tired from travelling, may not be alert and may be a foreign national who cannot understand safety advice or announcements. B1: Traffic management aspect with implications for emergency response include traffic volume, traffic speed, the nature of the vehicles using the tunnel. B3: First aid and fire fight equipment for the public have implications for possibilities to prevent escalation of events. The EOs need specialist equipment to deal with tunnel incidents, e.g. extended duration breathing apparatus and communication equipment functional in tunnels and across organizational boundaries. C1: There is a need to understand the implications of tunnel design on emergency response. B3 \& C1-C3: Tunnel design and technical equipment that has implications for emergency response e.g. length, cross sections, bi- or uni-directional flow, emergency refuges, fresh air ducts, jet fans, warning-system for drivers, sprinklers, carbon monoxide monitoring equipment. C3: Emergency response can be carried out by dedicated rapid response teams or by national emergency services. Some tunnels have 24 hour monitoring and surveillance with dedicated response teams. Some tunnels, that cross national boarders, have different operators responsible for different sections of the tunnel. D1: Pre-planning \& preparation is vital if assisted rescue and firefighting is to be affected quickly. Contingency plans need to be jointly developed in order to secure a coherent and coordinated approach to incident management. D2: Maintaining preparedness for tunnel incidents is often difficult in large organizations. D3: Commercial vehicle \& bus fires are seldom possible to put out, instead burning out on their own 
Table 4. Continued.

\begin{tabular}{|c|c|c|}
\hline $\begin{array}{l}\text { Ref. } \\
\#\end{array}$ & Authors, year and title & $\begin{array}{l}\text { Study design, type } \\
\text { of tunnel (scor- } \\
\text { ing/quality) }\end{array}$ \\
\hline [31] & $\begin{array}{l}\text { Statens Haverikom- } \\
\text { misjon for Transport, } \\
2015 \text { Report of truck fire } \\
\text { on the E16 in the Gud- } \\
\text { vangatunnel in Aurland } \\
\text { the } 5^{t h} \text { of August } 2013\end{array}$ & $\begin{array}{l}\text { Special report, Road } \\
\text { tunnel (Low) }\end{array}$ \\
\hline [32] & $\begin{array}{l}\text { Lockey et al., } 2005 . \\
\text { London bombings July } \\
\text { 2005: the immediate } \\
\text { prehospital medical re- } \\
\text { sponse }\end{array}$ & $\begin{array}{l}\text { Case study, Subway } \\
\text { (Medium) }\end{array}$ \\
\hline [33] & $\begin{array}{l}\text { Larsson, 2004. The tun- } \\
\text { nel accident in Kaprun }\end{array}$ & $\begin{array}{l}\text { Case study/report, } \\
\text { Furnicular (Medium) }\end{array}$ \\
\hline
\end{tabular}

Main findings/major factors according to Haddons matrix

A2-B2: Smoke exposure in a tunnel even when the fire is put out, dependent on natural wind and use of ventilation. A2-C2: Duration of smoke exposure is important for outcome. C3: Two command posts and evacuation sites, due to dual-direction of evacuees, imply added needs for coordination. Smoke divers may relay users to ambulances. Uncertain need for medical personnel in the tunnel. Ventilated smoke direction may hinder EMS staff ingress. Differing safety concerns between involved response organizations. Private cars and buses may augment transportation capabilities.

B3: Mobile network and telecommunication failed in underground. Full protective equipment vital. C3D3: Dual-direction evacuation led to assumption of two incidents. D2: Value of personnel experienced in pre-hospital environment. Control rooms isolated from operational teams. Poor working conditions. Helicopter availability essential for staff and equipment deployment. Scene safety a major concern.

A2-3 \& D3: Passengers who did not self-evacuate estimated to have perished prior to rescue service arrival. B2: No evacuation lighting. No possibility to call for help or contact driver. Unable to open doors to evacuate; some improvised opening by breaking side window. Electricity and communication network failed. B3: Radio use not possible due to location. Mobile network overloaded. C2: Staircase used to evacuate not purpose-built. C3-D3: Topography complicated rescue. D1-D3: Lack of safety policies and legislation demanding emergency routes were not considered necessary. Successful drills and evacuations were regularly carried out but such an explosive fire scenario had never been considered. Staff in the crisis management thought the incident was impossible and initially assumed that it was a drill. Staff at top station underestimated danger and were soon overwhelmed by smoke. The first one found by RS was the only one that survives. Experiences from the Tauern tunnel fire meant the crisis management organizations tried to limit the involved actors.

\begin{tabular}{lll}
\hline [34] & $\begin{array}{l}\text { Okumura et al., 1998. } \\
\text { The Tokyo Subway }\end{array}$ & $\begin{array}{l}\text { Case study, Subway } \\
\text { (Medium) }\end{array}$ \\
& $\begin{array}{l}\text { Sarin Attack: Disaster } \\
\text { Management, Part 1: } \\
\text { Community Emergency } \\
\text { Response }\end{array}$ & \\
\hline [35] & $\begin{array}{l}\text { Ryan \& Montgomery, } \\
\text { 2005. Terrorism and the } \\
\text { Medical Response }\end{array}$ & Case study, Subway \\
&
\end{tabular}

B3: PPE need to be available for prehospital personnel. D1-D3: No field decontamination was planned or took place during response. Around $10 \%$ of EMTs were secondarily exposed to sarin and needed treatment. EMTs were not allowed to maintain airway with endotracheal tube or laryngeal mask airway. Due to communication overload EMTs could not contact doctors. Could not get hospital availability information. Cases of delayed symptoms during transportation. Hospital personnel dispatched to scenes were not needed for advanced medical procedures.

B3: Communication infrastructure failed due to overload hampering coordination. C2: Confined spaces exacerbate effects of bomb detonations, increasing injury severity and resultant mortality. D3: Multiattack means pressure on EMS and demand on communication. Underground locations add problems of site access and safety, as well as the need for specialist training and extrication skills. Targeting and closing of transportation system lead to road congestion, preventing medical staff from reaching scene or hospital as well as patient discharge.

[36] Hallén \& Kulling, 1990. Case study/report, Fire at the King's Cross Subway (Medium) subway station on $18^{t h}$ of November 1987

B3: Radio equipment did not work underground. D3: Rescue services relayed casualties. A freelance doctor and a rescue worker died while trying to help People needed to be hosed down because their clothes were so hot and several had burns on their skin even though their clothes appeared unharmed. Many of those that succumbed did so from poisoning by hydrogen cyanide and oxygen deprivation.

[37] Sandersson et al., 2007. Special report, Rail B3: Sparse MANETs to overcome communication difficulties during response. Developing mobile mid- tunnel; Subway dle ware - an analysis of rescue and emergency operations

[38] Heltne, 2015. Truck and Perspective article, tunnel fire Road tunnel (Low)

B1-B3: Inadequate portable fire extinguishers. Unfuncional fans and lighting due to fire in the electrical system. B2 \& D3: Poor contact to mobile net due to location. Communications failure between personnel on different sides of tunnel. Partially successful use of cell phones and social media scanning. C3-D3: Initial traffic jam solved by change of traffic direction. D3: Delay in patient access due to transport patients due to rural area. Effective triage by HEMS, appropiate use of transportation and several hospitals involved in patient distribution. Different organizational districts, dual command posts, evacuation sites, and dispatch centers impeded communication and coordination.

[39] Tokuda et al., 2006. Prehospital management of sarin nerve gas terrorism in urban settings: 10 years of progress after the Tokyo subway sarin attack

[40] Carvel \& Marlair, 2005 A history of fire incidents in tunnels

Case study, Subway (Medium)

B3: No protective equipment for EMTs; $10 \%$ of EMTs poisoned. C2: Indoor setting lessened gas dispersal. D1: No plan for on-site decontamination. D3: Little cooperation and communication among emergency organizations. Distribution of casualties suboptimal due to communication failure.

[41] Manca \& Brambilla, 2011. A methodology based on the Analytic Hierarchy Process for the quantitative assessment of emer gency preparedness and response in road tunnels.

Special report, Road - Rail tunnels (Low)

Modelling study, Road tunnel (High)
A1-3: Human behavior in response to fires often detrimental to survival. B2: HGV presence contributed to fire load. Sucessful self-rescue thanks to sprinkler system. C2: Deaths due to heat in emergency shelters. C1 \& D1: Tunnel safety has to start at design stage.

B1 \& C1: Tunnel safety aspects include physical features e.g. slope, length, emergency exits, emergency lighting and its internal equipment e.g., sidewalks and sirens. C1 \& D1: Emergency response also dependent on contextual resources available in the neighboring areas of the tunnel e.g., hospitals, helipads, water basins. D1-D3: Written plans are important, but proper distribution of information during emergencies is required. Tunnel safety aspects include organizational aspects of the emergency preparedness and response e.g. definition of responsibility areas, roles, procedures. The training of responders affects the emergency response. 
Table 4. Continued.

\begin{tabular}{|c|c|c|c|}
\hline $\begin{array}{l}\text { Ref. } \\
\#\end{array}$ & Authors, year and title & $\begin{array}{l}\text { Study design, type } \\
\text { of tunnel (scor- } \\
\text { ing/quality) }\end{array}$ & Main findings/major factors according to Haddons matrix \\
\hline [43] & $\begin{array}{l}\text { Chalonel, 2005. Blast in- } \\
\text { jury in enclosed spaces. }\end{array}$ & $\begin{array}{l}\text { Special report, Other } \\
\text { (Low) }\end{array}$ & $\begin{array}{l}\text { A2 \& C2: Enclosed environments increase reflection of blast waves; greater mortality and severity of } \\
\text { injuries. }\end{array}$ \\
\hline [44] & $\begin{array}{l}\text { Olesen, } 2005 \text {. Emer- } \\
\text { gency procedures in rail } \\
\text { tunnels: current practice } \\
\text { and future ideas }\end{array}$ & $\begin{array}{l}\text { Special report, Rail } \\
\text { tunnel (Low) }\end{array}$ & $\begin{array}{l}\text { B2-B3: Danish rescue service have special rescue vehicles which can drive on both road and rail. C2-C3 } \\
\text { \& D2-D3: Rail compared to road tunnels, longer approach route, need for specialist vehicles for transport, } \\
\text { greater collective fire load. A major advantage is the presence of train personnel who can help improve } \\
\text { the situation. D1-D3: Incident procedures may be dependent on legislation and standard procedure } \\
\text { functions in and between authorities. Rules of engagement and approach to tunnel incidents by the } \\
\text { emergency medical services differs between countries due to legislation, equipment, prior experience } \\
\text { and the specific scenario and the condition of survivors. Due to lower risk of an incident in a rail tunnel } \\
\text { compared to roads the motivation and perceived necessity for safety and emergency procedures is less. } \\
\text { A simplified contingency plan up describing concrete actions of actors involved and coordination aspects } \\
\text { specified. Plans, procedures and action lists should be tested through small-scale exercise before major } \\
\text { validation exercise. }\end{array}$ \\
\hline [45] & $\begin{array}{l}\text { Lyon \& Sanders, } 2012 \text {. } \\
\text { The Swiss bus acci- } \\
\text { dent on } 13 \text { March } 2012 \text { : } \\
\text { lessons for pre-hospital } \\
\text { care }\end{array}$ & $\begin{array}{l}\text { Case study, Bus } \\
\text { (Medium) }\end{array}$ & $\begin{array}{l}\text { D2: Experienced pre-hospital doctors on-scene allowed advanced interventions. Experience in pedi- } \\
\text { atric trauma rare among EMS staff. D3: Pre-hospital pediatric triage more complex than adult triage. } \\
\text { Helicopter availability essential for staff and equipment deployment. }\end{array}$ \\
\hline [46] & $\begin{array}{l}\text { Helbing \& Mukerji, } 2012 . \\
\text { Crowd disasters as sys- } \\
\text { temic failures: Analysis } \\
\text { of the Love Parade Dis- } \\
\text { aster }\end{array}$ & $\begin{array}{l}\text { Case study/report, } \\
\text { Road tunnel } \\
\text { (Medium) }\end{array}$ & $\begin{array}{l}\text { D1-D3: Love Parade incident caused by "crowd turbulence". B1: Signs and loudspeaker announcements } \\
\text { were not available to inform public. B3 \& D3: Prompt action was delayed by communication problems. } \\
\text { C1-C3: Lack of recognizable and accessible emergency exits. D1: Event and disaster plan lacking to } \\
\text { avoid incident and minimize consequences. }\end{array}$ \\
\hline [47] & $\begin{array}{l}\text { Aylwin et al., } 2006 \text {. Re- } \\
\text { duction in critical mortal- } \\
\text { ity in urban mass casu- } \\
\text { alty incidents: analysis } \\
\text { of triage, surge, and re- } \\
\text { source use after the Lon- } \\
\text { don bombings on July } 7 \text {, } \\
2005\end{array}$ & $\begin{array}{l}\text { Case study, Subway } \\
\text { (Medium) }\end{array}$ & $\begin{array}{l}\text { D3: Number of incidents confused due to dual-direction evacuation. Over-triage rates lower at scenes } \\
\text { triaged by London HEMS. Triage errors and surge reduced by trained, experienced decision-makers. } \\
\text { Rate of casualty clearance hampered on underground scene due to scene access and patient extrication } \\
\text { issue, plus ambulance provision. }\end{array}$ \\
\hline [48] & $\begin{array}{l}\text { Bassi et al., 2014. As- } \\
\text { sistance of inhalation in- } \\
\text { jury victims caused by } \\
\text { fire in confined spaces: } \\
\text { what we learned from } \\
\text { the tragedy at Santa } \\
\text { Maria. }\end{array}$ & $\begin{array}{l}\text { Special report, Other } \\
\text { (Low) }\end{array}$ & D3: Inhalation injuries in confined spaces. \\
\hline [49] & $\begin{array}{l}\text { Petinaux et al., } 2014 \text {. } \\
\text { Confined space } \\
\text { medicine and the } \\
\text { medical management } \\
\text { of complex rescues: a } \\
\text { case series }\end{array}$ & $\begin{array}{l}\text { Retrospective case } \\
\text { series/ Comparative } \\
\text { case study, Other } \\
\text { (Medium) }\end{array}$ & $\begin{array}{l}\text { A3 \& D3: Bystanders and first responders accomplish many post-collapse rescues but some victims } \\
\text { may be deeply entombed, making detection difficult and requiring sophisticated rescue resources. D3: } \\
\text { Few published reports document the specific medical challenges encountered in rescues of entrapped } \\
\text { patients, more commonly focusing on the patients' condition after entrapment. Rescue from a collapsed } \\
\text { structure can pose significant risk to the responders. }\end{array}$ \\
\hline [50] & $\begin{array}{l}\text { Berlin et al., } 2010 . \\
\text { Providers improvise } \\
\text { with confined space } \\
\text { patient }\end{array}$ & $\begin{array}{l}\text { Non-systematic } \\
\text { review/guideline, } \\
\text { Other (Low) }\end{array}$ & $\begin{array}{l}\text { B3 \& D3: Prehospital care of crush injuries. Early, aggressive treatment of hyperkalemia necessary for } \\
\text { survival. }\end{array}$ \\
\hline
\end{tabular}




\section{Discussion}

This literature review shows that few studies, especially of high quality, actually provide detailed information regarding emergency response to tunnel incidents and those that do, often have a main focus on management by the RS. While many incidents studied were caused by fires in tunnels, thus requiring $\mathrm{RS}$ action, the subsequent EMS response issues that have taken place appear to have been given limited attention. Important exceptions to this inadequacy were several reports from the London bombings and the Tokyo sarin attack, both of which were of antagonistic origin. The lack of studies inhibits efforts to optimize the survival rates and health of the injured in $\mathrm{MCl}$ in tunnels, as well as efforts to provide a safe and effective work environment for EMS responders.

This review found a heavy focus on pre-event factors. Studies repeatedly highlighted that heat and smoke quickly create a fatal environment, which in turn means that scene safety is a huge concern in tunnel environments. Tunnel design may also have further implications for the EMS response. Regarding the EMS response, research highlights communication issues due to overload or non-functional radios in tunnel environments, difficulties with getting an overview of the scene, and the lack of real-life experience or training in this specific environment, which could impede the evacuation and EMS response. Overall, there is a need for more research including the EMS perspective regarding tunnel incidents and training, but much can likely be clarified by merging already existent research and future projects using inter-disciplinary approaches, but also for a more extensive collaboration between different actors in the construction phase of tunnels. Compared to research on e.g. the injury mechanisms of terrorist attacks [51], studies of the medical response to tunnel incidents are clearly lacking.

This review also found that safety is a huge concern. There are several safety-limitations for the EMS to apply offensive operational tactics in a threatened tunnel tube. Offensive action might result in endangering the lives of EMS responders, while the effects in terms of rescue are highly uncertain. In case of a fire, the conditions like visibility and temperature have usually deteriorated in such a way that an effective rescue operation is risky [25].

In the included studies, it has been shown that if an incident occurs in a tunnel, the immediate mortality rate and severity of injuries increase and the consequences may further be worsened as emergency services can be impeded from swift access and are constrained from using their normal work practices. Recent medical development and EMS training, such as the use of tourniquets and rapid transport to advanced trauma centers, has meant that injuries sustained in bombings, such as traumatic amputations, that were once considered a marker for a lethal outcome, are now survivable $[51,52]$.

\subsection{Conclusion}

There is a need to increase the specific knowledge of EMS response during major incidents in tunnels. To optimize the survival rates and health of the injured, as well as to provide a safe and effective work environment for the emergency services, there is a need to explore the event phase. Knowledge gained from the incident's post-event phase and through exercises need to be explored, to better prepare responders for joint effective tactics. When it comes to prevention of $\mathrm{MCl}$, there is also a lot to learn from table-top and full-scale exercises and actions taken when low-scale incidents were prevented from becoming large-scaled.

Further investigation of specific challenges regarding information exchange, collaboration and initiatives for knowledge transfer between responders to provide prehospital care, and how to establish joint efforts in the emergency response (specifically during the initial event phase) is needed. Similarly, with regard to EMS care in major tunnel incidents where more offensive interventions are far away, preparation and practice is lacking.

\subsection{Limitations}

This study had the ambition to review information about emergency response and EMS care associated with incidents in tunnels. However, the existing literature presented few such examples, resulting in the inclusion of related issues and grey literature to a larger degree than initially planned.

Aspects that were problematic to fully map out were those that precede the care during rescue operations in tunnels. The difficulty in finding these issues partly lies in the systematic literature search methodology. It was a balance act to identify preventive actions that directly impacted the need and possibilities for an effective EMS response without also including indirect matters. It was especially challenging to find relevant information if "embedded" or surrounded by clearly irrelevant information, which resulted in the inclusion of articles that contained only a sentence or two of interest. Thus, the precondition aspects may not have been fully mapped out as, for example, studies focusing on technical matters and human behaviors in tunnel incidents were excluded while these might have (at least secondary) essential impact on EMS response and care.

\section{Acknowledgements}

We are grateful to The Swedish National Board of Health and Welfare and Umea University for funding. 


\section{References and Notes}

[1] Ardagh MW, Richardson SK, Robinson V, Than M, Gee P, Henderson S, et al. The Initial Health-system Response to the Earthquake in Christchurch, New Zealand, in February, 2011. The Lancet. 2012;379(9831):2109-2115. doi:10.1016/s0140-6736(12)60313-4.

[2] Philippe JM, Brahic O, Carli P, Tourtier JP, Riou B, Vallet B. French Ministry of Health's response to Paris attacks of 13 November 2015. Critical Care. 2016;20(1). doi:10.1186/s13054-016-1259-8.

[3] Koning SW, Ellerbroek PM, Leenen LPH. Indoor Fire in a Nursing Home: Evaluation of the Medical Response to a Mass Casualty Incident Based on a Standardized Protocol. European Journal of Trauma and Emergency Surgery. 2014;41(2):167-178. doi:10.1007/s00068014-0446-z.

[4] Biddinger PD, Baggish A, Harrington L, d'Hemecourt P, Hooley $\mathrm{J}$, Jones $\mathrm{J}$, et al. Be Prepared - The Boston Marathon and Mass-Casualty Events. New England Journal of Medicine. 2013;368(21):1958-1960. doi:10.1056/nejmp1305480.

[5] Hardy S, Fattah S, Wisborg T, Raatiniemi L, Staff T, Rehn M. Correction to: Systematic Reporting to Improve the Emergency Medical Response to Major Incidents: A Pilot Study. BMC Emergency Medicine. 2018;18(1). doi:10.1186/s12873-018-0157-6.

[6] Rohlén P, B W. Major accidents-The subway Fire in Baku, Azerbaijan 28th of October 1995; 1996. P22-133/96.

[7] Bergmeister K, Francesconi S. Causes and Frequencies of Incidents in Tunnels. Trento, Italy: UPTUN - Upgrading of Existing Tunnels; 2004. GRD1-2001-40739.

[8] Mortimer C. North Korea Tunnel Collapse at Nuclear Test Site Could Cause Serious Radiation Leak. Available from: https://www.independent.co.uk/news/world/asia/north-korea-tunnelnuclear-test-site-radiation-leak-punggye-ri-kim-jong-un-war-usa8033161.html.

[9] Haack A. Current Safety Issues in Traffic Tunnels. Tunnelling and Underground Space Technology. 2002;17(2):117-127. doi:10.1016/s0886-7798(02)00013-5.

[10] Koumpis K, Hailes S, Hanna L. Tunnels of Terror [Emergency Response]. Computing and Control Engineering. 2006;17(1):14-19. doi:10.1049/cce:20060102.

[11] Amundsen FH, Ranes G. Studies on Traffic Accidents in Norwegian Road Tunnels. Tunnelling and Underground Space Technology. 2000;15(1):3-11. doi:10.1016/s0886-7798(00)00024-9.

[12] Experience with Significant Incidents in Road Tunnels. PIARC - World Road Association; 2016.

[13] Santos-Reyes J, Beard AN. An Analysis of the Emergency Response System of the 1996 Channel Tunnel Fire. Tunnelling and Underground Space Technology. 2017;65:121-139. doi:10.1016/j.tust.2017.02.011.

[14] McDaniel K. A New Methodology to Evaluate Critical Fire Life Safety and Emergency Prepredness in Vehicular Road Tunnels; 2017. Available from: https://mountainscholar.org/bitstream/handle/11124/ 170970/McDaniel_mines_0052E_11224.pdf?sequence $=1$.

[15] Njå O, Svela M. A Review of Competencies in Tunnel Fire Response Seen from the First Responders' Perspectives. Fire Safety Journal. 2018;97:137-145. doi:10.1016/j.firesaf.2017.05.005.

[16] Palm A. Tactics and Command During Fires in Underground Structures: Analysis of Fullscale Trials and Tree Real Life Events.; 2014. 2.

[17] Torraco RJ. Writing Integrative Literature Reviews: Guidelines and Examples. Human Resource Development Review. 2005;4(3):356367. doi: $10.1177 / 1534484305278283$.

[18] Evaluation of Methods in Public Health and Health Care: A Handbook (in Swedish). The Swedish State Advisory Committee on Assessment of Health Care Interventions; 2013.

[19] Holgersson A. Review of On-Scene Management of MassCasualty Attacks. Journal of Human Security. 2016;12. doi:10.12924/johs2016.12010091.

[20] Haddon W. Advances in the Epidemiology of Injuries as a Basis for Public Policy. Public Health Reports. 1980;95(5):411-421. Available from: http://www.jstor.org/stable/4596353.

[21] Haddon WJ, Baker S. Injury Control. In: Clark W, B M, editors. Preventive and Community Medicine. 2nd ed. Little, Brown and Company; 1981. pp. 109-140.
[22] Mackway-Jones K. Major Incident Medical Management and Support. Wiley-Blackwell; 2011. doi:10.1002/9781444398236.

[23] Vuilleumier F, Weatherill A, Crausaz B. Safety Aspects of Railway and Road Tunnel: Example of the Lötschberg Railway Tunnel and MontBlanc Road Tunnel. Tunnelling and Underground Space Technology. 2002;17(2):153-158. doi:10.1016/s0886-7798(02)00018-4.

[24] Ernst S, Patel M, Capers H, Dwyer D, Hawkins C, Jakovich G, et al. Underground Transportation Systems in Europe: Safety Operations and Emergency Response. American Trade Initiatives; 2006. FHWAPL-06-016. Available from: https://international.fhwa.dot.gov/uts/uts. pdf.

[25] Rosmuller N, Van den Brand R. Emergency Response Possibilities at Freight Railway Tunnel Accidents. International Journal of Emergency Management. 2003;1(4):374. doi:10.1504/ijem.2003.004359.

[26] Berqvist A, Frantzich H, Hasselrot K, Ingason H. 23. Fire and Rescue Operations in Tunnel Fires: a Discussion of Some Practical Issues. In: The Handbook of Tunnel Fire Safety. Thomas Telford Publishing; 2005. pp. 481-503. doi:10.1680/hotfs.31685.0023.

[27] Ingason H, Bergqvist A, Lönnemark A, Frantzich $\mathrm{H}$, Hasselrot $\mathrm{K}$. Rescue in Road Tunnels; 2005. Report No.: P21-459/05.

[28] Bruyelle JL, O'Neill C, El-Koursi EM, Hamelin F, Sartori N, Khoudour L. Improving the Resilience of Metro Vehicle and Passengers for an Effective Emergency Response to Terrorist Attacks. Safety Science. 2014;62:37-45. doi:10.1016/j.ssci.2013.07.022.

[29] Voeltzel A, Dix A. A Comparative Analysis of the Mont-Blanc, Tauern and Gothard Tunnel Fires. Routes/Roads. 2004;324:18-34. Available from: http://worldcat.org/oclc/31984593.

[30] Burns D. 21. Emergency Procedures in Road Tunnels: Current Practice and Future Ideas. In: The Handbook of Tunnel Fire Safety. Thomas Telford Publishing; 2005. pp. 435-450. doi:10.1680/hotfs.31685.0021.

[31] Statens Havarikommisjon for Transport. Report of Fire in Truck on E16 in the Gudvangatunnel in Aurland, August 5 2013. African Affairs; 2015. Report No.: Vei 2015:02.

[32] Lockey DJ, MacKenzie R, Redhead J, Wise D, Harris T, Weaver A, et al. London Bombings July 2005: The Immediate Prehospital Medical Response. Resuscitation. 2005;66(2):ix-xii. doi:10.1016/j.resuscitation.2005.07.005.

[33] The Tunnel Accident in Kaprun 2000 (in Swedish). Crismart; 2004.

[34] Okumura T, Suzuki K, Fukuda A, Kohama A, Takasu N, Ishimatsu S, et al. The Tokyo Subway Sarin Attack: Disaster Management, Part 1 : Community Emergency Response. Academic Emergency Medicine. 1998;5(6):613-617. doi:10.1111/j.1553-2712.1998.tb02470.x.

[35] Ryan J, Montgomery $\mathrm{H}$. Terrorism and the Medical Response. New England Journal of Medicine. 2005;353(6):543-545. doi:10.1056/nejmp058177.

[36] Hallén B, Kulling P. The Fire at the King's Cross Subway Station on the 18th of November 1987. The Swedish National Board of Health and Welfare; 1990. 30.

[37] Norun C, Sanderson K, Skjelsvik, Ovidiu V, Drugan M, Pužar V, et al. Developing Mobile Middleware-An Analysis of Rescue and Emergency Operations; 2007. 358.

[38] Heltne JK. Truck and tunnel fire. Major Incident Reporting. Norwegian Air Ambulance and London's Air Ambulance;. Available from: http:// majorincidentreporting.net/wp-content/uploads/2015/12/heltne.pdf.

[39] Tokuda Y, Kikuchi M, Takahashi O, Stein GH. Prehospital Management of Sarin Nerve Gas Terrorism in Urban Settings: 10 Years of Progress After the Tokyo Subway Sarin Attack. Resuscitation. 2006;68(2):193-202. doi:10.1016/j.resuscitation.2005.05.023.

[40] Carvel R, Marlair G. 1. A History of Fire Incidents in Tunnels. In: The Handbook of Tunnel Fire Safety. Thomas Telford Publishing; 2005. pp. 1-41. doi:10.1680/hotfs.31685.0001.

[41] Manca D, Brambilla S. A Methodology Based on the Analytic Hierarchy Process for the Quantitative Assessment of Emergency Preparedness and Response in Road Tunnels. Transport Policy. 2011;18(5):657-664. doi:10.1016/j.tranpol.2010.12.003.

[42] Baker D, Murrey V. Emergency Medical and Public Health Responses to the 2005 London Bombings. In: Integrated Emergency Management for Mass Emergencies. ProQuest Ebook Central: IOS Press; 2013. doi:10.3233/978-1-61499-311-7-74.

[43] Chaloner E. Blast Injury in Enclosed Spaces. 2005;331(7509):119-120. doi:10.1136/bmj.331.7509.119.
BMJ. 
[44] Olesen J, Fire Brigade K. 22. Emergency Procedures in Rail Tunnels: Current Practice and Future Ideas. In: The Handbook of Tunnel Fire Safety. Thomas Telford Publishing; 2005. pp. 451-480. doi:10.1680/hotfs.31685.0022.

[45] Lyon RM, Sanders J. The Swiss Bus Accident on 13 March 2012: Lessons for Pre-hospital Care. Critical Care. 2012;16(4):138. doi:10.1186/cc11370.

[46] Helbing D, Mukerji P. Crowd Disasters as Systemic Failures: Analysis of the Love Parade Disaster. EPJ Data Science. 2012;1(1). doi:10.1140/epjds7.

[47] Aylwin CJ, König TC, Brennan NW, Shirley PJ, Davies G, Walsh MS, et al. Reduction in Critical Mortality in Urban Mass Casualty Incidents: Analysis of Triage, Surge, and Resource Use After the London Bombings on July 7, 2005. The Lancet. 2006;368(9554):2219-2225. doi:10.1016/s0140-6736(06)69896-6.

[48] Bassi E, Costa-Miranda L, G M M PFT, Biselli-Ferreira C, Cadamuro FM, Figueiredo VR, et al. Assistance of Inhalation Injury Victims Caused by Fire in Confined Spaces: What We Learned from the
Tragedy at Santa Maria. Revista Brasileira de Terapia Intensiva. 2014;26(4). doi:10.5935/0103-507x.20140065.

[49] Petinaux B, Macintyre AG, Barbera JA. Confined Space Medicine and the Medical Management of Complex Rescues: A Case Series. Disaster Medicine and Public Health Preparedness. 2014;8(1):20-29. doi:10.1017/dmp.2014.1.

[50] Berlin P, North G, Okamoto D. Providers Improvise with Confined Space Patients. Journal of Emergency Medical Services. 2010;35(11):44-46. Available from: https://www.jems.com/2010/ 10/31/providers-improvise-confined-s/.

[51] Patel HDL, Dryden S, Gupta A, Chai Ang S. Pattern and Mechanism of Traumatic Limb Amputations After Explosive Blast. Journal of Trauma and Acute Care Surgery. 2012;73(1):276-281. doi:10.1097/ta.0b013e318256dd80.

[52] Langworthy MJ, Sabra J, Gould M. Terrorism and Blast Phenomena. Clinical Orthopaedics and Related Research. 2004;422:82-87. doi:10.1097/01.blo.0000128293.43913.ca. 